\title{
Levantamento das atividades de reuso e reciclagem têxtil na região metropolitana do Rio de Janeiro
}

\author{
Study of reuse and recycling activities in the metropolitan \\ region of Rio de Janeiro \\ Welton Fernando Zonatti ${ }^{\mathrm{a}}$ \\ Frederico Brandão de Araújob \\ Heloísa Nazaré dos Santos ${ }^{c}$ \\ Júlia Baruque-Ramos $^{d}$
}

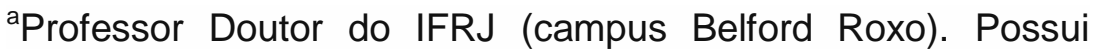
Doutorado em Sustentabilidade pela USP-EACH, Mestrado e Graduação em Têxtil e Moda também pela USP-EACH. Possui pesquisa ligada às áreas do ecodesign de moda, da sustentabilidade e do reuso/reciclagem têxtil. E-mail: welton.zonatti@ifrj.edu.br

${ }^{\text {b}}$ Graduando em Produção Cultural pelo IFRJ. Tem experiência nas áreas de teatro, cinema e economia solidária; E-mail: fbprocult@gmail.com
\end{abstract}

'Profa. Ma. da Escola de Design da UEMG. Possui graduação em Desenho Industrial e Educação Artística, e Mestrado em Engenharia de Produção. Atualmente é doutoranda em Engenharia de Materiais. Tem experiências nas áreas de gestão e produção.E-mail: heloisa.santos@uemg.br

'Profa. Associada da USP-EACH. Possui Doutorado, Mestrado e Graduação em Engenharia Química pela POLI-USP. Experiência nas áreas de tecnologia têxtil e biotecnologia. Email: jbaruque@usp.br

Recebido em: 20/11/2016 I Aceito em: 02/12/2016 
Levantamento das atividades de reuso e

reciclagem têxtil na região metropolitana

do Rio de Janeiro

ARTIGO

\title{
RESUMO
}

O Brasil configura-se como um dos maiores produtores mundiais do setor têxtilconfeccionista. É um importante produtor da fibra de algodão, de fios, de tecidos planos e de malha, além de estimular o PIB do país gerando milhões de empregos diretos e indiretos no referido setor. Contudo, tal atividade cria diversos problemas ambientais, como por exemplo, a geração de resíduos sólidos oriundos dos processos industriais, confeccionistas e também do pósconsumo. São produzidas, anualmente, 175 mil toneladas de aparas têxteis advindas somente dos cortes dos enfestos nas confecções brasileiras, posto que mais de $90 \%$ desses resíduos de tecidos são descartados incorretamente. Deste modo, o presente artigo apresenta um breve histórico sobre o surgimento da Sustentabilidade como campo de pesquisa, bem como apresenta considerações sobre a geração de resíduos sólidos na cadeia têxtil brasileira, além de abarcar exemplos de atividades de reuso e reciclagem têxtil presentes na região metropolitana do Rio de Janeiro. Tais atividades podemcontribuir para a diminuição de problemas ambientais, além de constituir uma fonte de renda economicamente viável para todos envolvidos em sua cadeia.

Palavras-chave: Sustentabilidade. Indústria Têxtil-Confeccionista. Reuso e Reciclagem Têxtil.

\begin{abstract}
Brazil is one of the largest world producers of textiles and clothing. It is an important producer of cotton fiber, yarn, plain and knitted fabrics. This stimulates the country's GDP generating millions of direct and indirect jobs in this sector. However, such activity generates various environmental problems, such as the generation of solid waste from textile and clothing industrial processes, as well as the post-consumer clothing. In Brazilian apparel industry are produced, annually, 175,000 tons of textile trimmings from yours industries. More than $90 \%$ of these residues are discarded incorrectly. Thus, this study presents a brief history about the emergence of Sustainability as a field of research, as well presents considerations about solid waste generation in the Brazilian textile chain and gives examples of textile reuse and recycling activities in the metropolitan region from Rio de Janeiro.Such activities could contribute to the reduction of environmental problems, in addition to being an economically viable source of income for all involved in this chain.
\end{abstract}

Keywords: Sustainability. Textile-clothing manufacturer industry. Reuse and textile recycling. 


\section{INTRODUÇÃO}

O Brasil é um importante produtor têxtil-confeccionista, como demonstram dados obtidos pela ABIT - Associação Brasileira da Indústria Têxtil e de Confecção (2011). Tem uma significativa produção de fibras naturais, em especial a de algodão (ABIT, 2011), além de possuir relevância na produção de tecidos planos e de malha (FINKLER et al., 2005), bem como de artigos confeccionados (IEMI, 2014; IEMI, 2015). Deste modo, tal atividade industrial fomenta a criação de empregos e a geração de renda de milhões de trabalhadores (NEULS, 2012).

Constata-se, ainda, que a região sudeste é a principal produtora de têxteis no país, pois concentra os maiores mercados consumidores e também sedia os principais centros de distribuição de atacado e varejo (SINDIFIATEC, 2013; IEMI, 2014; IEMI, 2015). O Estado do Rio de Janeiro possui importantes APL - Arranjos Produtivos Locais, segundo dados da SEDEIS - Secretaria de Desenvolvimento Econômico, Energia, Indústria e Serviços do Estado do Rio de janeiro (2016).

Todavia, mesmo trazendo benefícios econômicos ao país, o setor têxtil e de confecção cria diversos problemas ambientais. Os diferentes processos de manufatura têxtil-confeccionista geram resíduos diversos, como restos de fios e também de tecidos (SINDITÊXTIL-SP, 2009). O SINDITÊXTIL-SP - Sindicato das Indústrias de Fiação e Tecelagem do Estado de São Paulo (2012) alerta pra o volume de sobras de tecidos oriundo dos cortes dos enfestos das confecções em nível nacional.

Observa-se que, a partir de 2007, a Sustentabilidade consolidou-se como uma área autônoma de pesquisa, sendo utilizada como embasamento para pesquisas e estudos de caso que visem a melhoria da vida dos indivíduos (NAS, 2007). No caso da indústria têxtil-confeccionista, atitudes para a não geração de resíduos ou mesmo para a minimização do volume de sobras devem ser tomadas pelo setor (SINDITÊXTIL-SP, 2009). 
Deste modo, as atividades de reuso e reciclagem têxtil também podem ser viáveis quanto à pretensão de destinar os resíduos de um modo mais sustentável, bem como pode vir a ser fonte de geração de renda para indivíduos ligados ao setor (ZONATTI, 2013; ZONATTI, 2016).

\section{METODOLOGIA}

As metodologias de pesquisa não convencionais ou alternativas tem como objetivo buscar novos caminhos para realidades cada vez mais complexas e dinâmicas e são tidas como pesquisas distintas das convencionais. Essas abordagens utilizam-se, com maior frequência, de análises qualitativas, tendo as descrições como uma significativa contribuição para a pesquisa (MARTINS, 1994).

A finalidade do presente trabalho tem um caráter de pesquisa aplicada, pois ela é "fundamentalmente motivada pela necessidade de resolver problemas concretos, mais imediatos ou não" (VERGARA, 2000).

Já o objetivo deste artigo é de pesquisa exploratória, uma vez que proporciona ao pesquisador maior familiaridade com o problema, tendo como principal objetivo o aperfeiçoamento de conceitos ou revelar novas concepções sobre eles (GIL, 2008).

Assim, foi realizada uma revisão crítica baseada na literatura. A pesquisa exploratória fornece mais informações sobre o assunto e facilita a definição do tema (MARCONI; LAKATOS, 2002). As referências analisadas baseiam-se: no surgimento da Sustentabilidade como campo de estudo; nos dados sobre o setor têxtil-confeccionista nacional - em especial o da região sudeste e sua relação com os impactos ambientais; no levantamento de dados sobre as atividades de reuso e reciclagem têxtil na região metropolitana do Rio de Janeiro.

Além disso, o presente artigo possui uma pesquisa descritiva, apresentando características de determinado fenômeno, firmando correlações entre variáveis e definindo sua natureza (VERGARA, 2000). Gil (2008) afirma 
que algumas pesquisas descritivas vão além da simples identificação da existência de relações entre variáveis, pretendendo determinar a natureza dessa relação.

Deste modo, para o desenvolvimento deste trabalho, optou-se por uma abordagem mais qualitativa de natureza exploratório-descritiva.

Além disso, a fim de observar in loco o trabalho de reuso de têxteis e de roupas descartadas, foi realizada uma visita técnica à escola Estadual "Benjamin Constant", situada à Travessa Mário Tinoco, s/n, Barreto (Figura 1), no dia 06 de Junho de 2016. Anteriormente em fase de desativação, foi cedida ao município de Niterói/RJ para funcionar como um dos espaços do Projeto EcoModa, de responsabilidade do estilista Sr. Almir França.

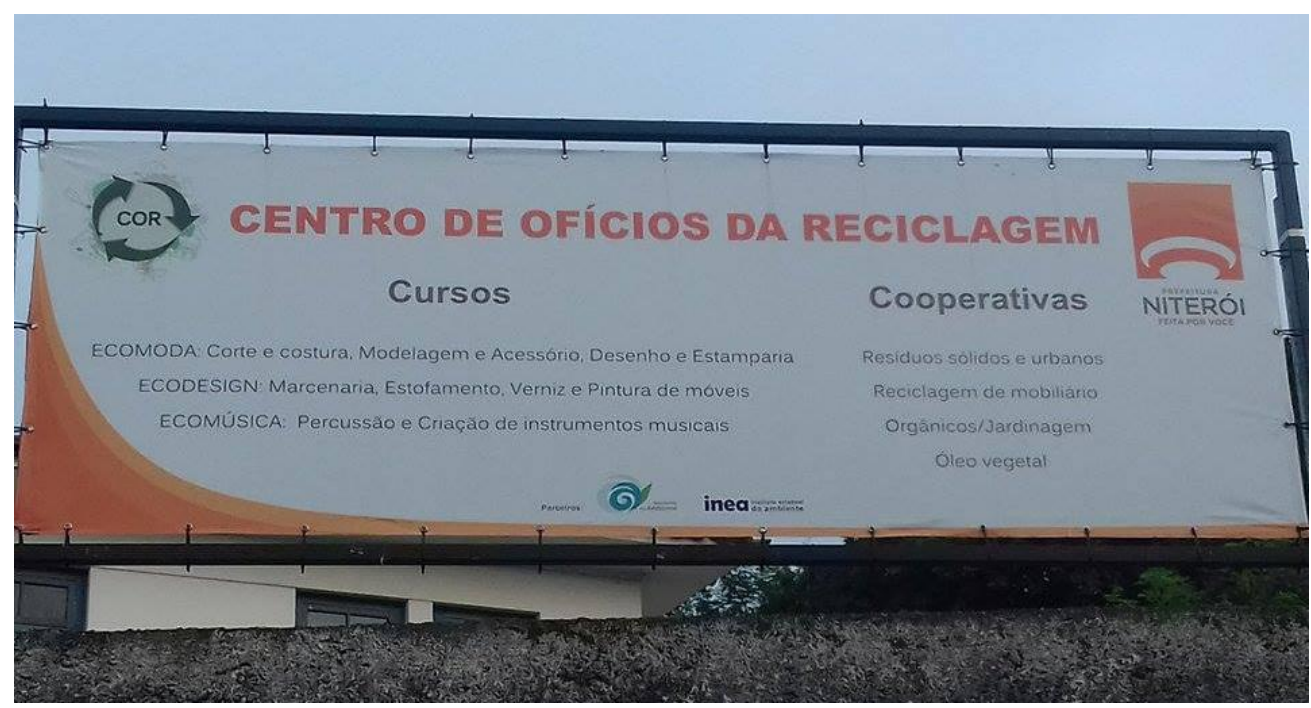

Figura 1: Antiga escola Estadual "Benjamin Constant", onde está situado o "Centro de Ofícios de Reciclagem" e onde realiza-se o projeto EcoModa, entre outros projetos Fonte: (Foto do autor)

\subsection{O surgimento da Sustentabilidade como campo de pesquisa inspirada pelo} uso

A National Academy of Sciences (NAS) ou Academia Nacional de Ciências dos Estados Unidos observou uma crescente demanda no que tange a Sustentabilidade, como: bolsas de estudo, disciplinas, artigos, congressos, escolas e institutos, além dos journals. Deste modo, em 2007, publicou um 
Levantamento das atividades de reuso e reciclagem têxtil na região metropolitana do Rio de Janeiro

editorial intitulado "Sustainability Science: A room of its own". A partir desta publicação,observou-se o aumento de quase $20 \%$ ao ano de artigos relacionados à Sustentabilidade, oriundos de áreas como ciências sociais, medicina e engenharia (NAS, 2007).

Assim, a NAS aprovou uma sessão de estudos em Sustentabilidade, consolidando esta área do conhecimento como uma ciência autônoma, não precisando mais ser empregada como uma "vertente" de outras ciências, como a biologia, a química, a sociologia, entre outras. Hoje, o campo desenvolveu uma agenda de pesquisa com um crescente fluxo de resultados e também um crescente número de universidades comprometidas em ensinar seus métodos e resultados. Assim como as ciências agrícolas e as ciências da saúde, a ciência da Sustentabilidade é um campo definido pelos problemas que aborda e não por disciplinas que emprega (NAS, 2007), baseando-se na interdisciplinaridade (MELO NETO; STACCIARINI, 2011; SILVA, 2000).

O conceito de Sustentabilidade, primeiramente concebido como "Desenvolvimento Sustentável", começou a ser elaborado em 1973, um ano depois da Primeira Conferência Mundial sobre o Homem e o Meio Ambiente ou Conferência de Estocolmo, mas sua projeção mundial só ocorreu em 1987 (PEREIRA, 2011). Em 1972, a Conferência de Estocolmo foi um grande marco ambiental, pois chamou a atenção do mundo para a gravidade da situação nesta área e a delegação brasileira assinou sem reservas a Declaração de Estocolmo. Em consequência, Henrique Brandão Cavalcanti, Secretário Geral do Ministério do Interior e membro da delegação brasileira na época, ao retornar ao Brasil, promoveu a elaboração do Decreto que instituiu em 1973 a Secretaria Especial do Meio Ambiente (TOZONI-REIS, 2002).

A Sustentabilidade compreende as complexas dinâmicas que surgem da relação homem-meio ambiente (NAS, 2007) e se baseia também no processo político-participativo que integra sustentabilidades ambiental, econômica, cultural, social e territorial. Contemplando, assim, equilíbrios coletivos e individuais, para o alcance e a manutenção da qualidade de vida, seja nos momentos de presença de recursos ou quando há períodos de escassez, cujas perspectivas são a cooperação e a solidariedade entre os povos e as gerações 
(KATES et al, 2001). Assim, faz-se necessário resgatar e construir um conjunto de ações e reflexões que propicie atitudes compromissadas com outro paradigma de sociedade e organização social, apontado para a importância do sentido de pertencimento, participação e responsabilidade (YOUNG; HAMSHIRE, 2000).

Além disso, a Sustentabilidade procura facilitar o que a National Research Council (NRC) ou Conselho Nacional de Pesquisa dos Estados Unidos nomeia de "transição para a Sustentabilidade" através das seguintes indagações (NAS, 2007):

i) Como podem as interações entre "homem x meio-ambiente" serem melhor incorporadas em modelos emergentes que integrem a capacidade da Terra e o desenvolvimento sustentável?

ii) Como são as tendências, a longo prazo, em relação às interações homem-natureza?

iii) Quais os fatores que determinam os limites de resiliência e as fontes de vulnerabilidade?

iv) Quais incentivos são mais eficazes para melhorar a capacidade social em buscar formas de vida e de produção mais sustentáveis?

v) Como pode a ciência e a tecnologia serem melhores aproveitadas afim de promover a sustentabilidade?

Delineados pela Cúpula Mundial sobre Desenvolvimento Sustentável, realizada em 2002 em Joanesburgo, na África do Sul, também são objetivos da Sustentabilidade (NAS, 2007; LAGO, 2006; UNITED NATIONS, 2016):

i) Promover melhoria no acesso à água potável e em quantidade suficiente;

ii) Avançar nos estudos sobre energia limpa e fabricação de produtos sustentáveis;

iii) Melhorar a produção agrícola e a segurança alimentar; orientar as rápidas urbanizações; estudar o uso mais eficaz dos recursos naturais para diminuir a pobreza; 
iv) Estudar sobre mudanças climáticas; estudar sobre a conservação do ecossistema e a conservação da biodiversidade.

Deste modo, pesquisadores que buscam promover a transição para a Sustentabilidade devem se engajar em pesquisas de ponta e em pesquisas que vão desde os sistemas complexos culturais à ecologia política (NAS, 2007) e, diferentemente das pesquisas puras ou aplicadas, a Sustentabilidade é a pesquisa básica inspirada pelo uso - remetendo ao Quadrante de Pasteur desenvolvido por Stokes (2008) (Figura 2), uma vez que o uso desta ciência resulta numa aplicação real no que tange a melhoria da qualidade de vida dos indivíduos em diversas esferas.

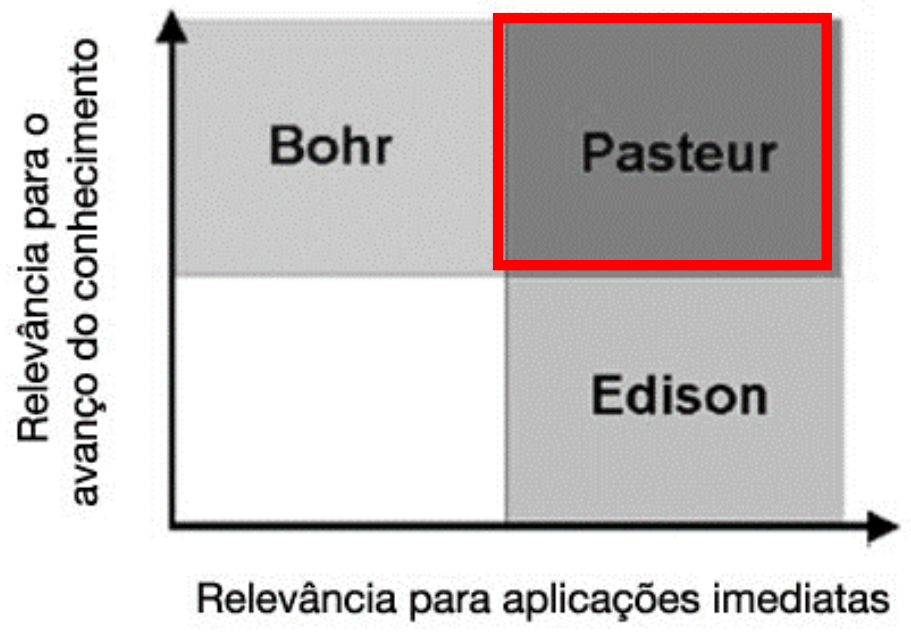

Figura 2: Quadrante de Pasteur Fonte: (IPT, 2016)

O Quadrante leva este nome por conta do cientista Louis Pasteur, que buscava um entendimento fundamental de seus estudos para aplica-los na área da microbiologia, tais como: formas de controlar a deterioração e a fermentação do vinagre, cerveja, vinho e leite; combater o antraz bovino e ovino, a cólera do frango e a raiva em animais e pessoas (GEISON, 1995). Os outros dois quadrantes dizem respeito à Neils Bohr, que desenvolveu o modelo atômico realizando uma pesquisa pura e não aplicada, e Thomas Edison, que produziu, comercialmente, a lâmpada elétrica utilizando o pressupostoda nãobusca de seu entendimento fundamental, baseando-se em um saber científico já disponível(STOKES, 2008). 
Stokes (2008), embasado nos estudos de Pasteur, afirma que toda pesquisa realizada por ele objetivoua busca pela ciência básica, seu entendimento e sua posterior aplicação. Deste modo, a pesquisa básica pode ser influenciada pelas aplicações reais e não deve ser vista como uma remota geradora de descobertas movida por curiosidade (STOKES, 2008).

\subsection{Problemas ambientais causados pela indústria têxtil e de confecção}

Além de ser um grande produtor de bens e de serviços em setores como o agrícola, o de mineração e o de petróleo (MATTOS, 2006), o Brasil também é um importante produtor mundial de artigos têxteis: $05^{\circ}$ maior produtor mundial, com uma produção aproximada de 1,8 milhões de toneladas de artigos confeccionados, por ano (IEMI, 2014; IEMI, 2015), e também o 5o maior produtor mundial de algodão (ABIT, 2011), ainda uma das fibras naturais mais consumidas no mundo (BASRA; MALIK, 1989), com a qual são feitas $60 \%$ das peças de vestuário confeccionadas no país (MELLO et al, 2007; ABIT, 2011). O Brasil ocupa a $7^{\text {a }}$ posição na produção de fios e tecidos planos e a $3^{\text {a }}$ na produção de tecidos de malha (FINKLER et al., 2005), além de gerar 8 milhões de empregos diretos e indiretos (NEULS, 2012).

O Sudeste é a principal região produtora de têxteis no país, pois concentra os maiores mercados consumidores e também sedia os principais centros de distribuição de atacado e varejo do Brasil, tendo perdido parcelas importantes de suas participações para as regiões Nordeste, Centro-Oeste e Sul do país entre 2009 e 2014 (SINDIFIATEC, 2013; IEMI, 2014; IEMI, 2015).

O Estado do Rio de Janeiro possui importantes APL - Arranjos Produtivos Locais, segundo dados da SEDEIS - Secretaria de Desenvolvimento Econômico, Energia, Indústria e Serviços do Estado do Rio de janeiro (2016). Dos 20 APL formalmente estabelecidos, 6 são voltados à indústria confeccionista e da moda, a saber: APL de Moda Íntima (Região Serrana); APL de Confecção de Moda Praia (Baixadas Litorâneas); APL de Confecção (Região Noroeste); APL Moda Carioca (Região Metropolitana); APL de 
Calçados e Acessórios da Baixada Fluminense (Região Metropolitana); e APL de Calçados e Acessórios (Região Médio Paraíba).

Contudo, mesmo trazendo benefícios econômicos ao país, o setor têxtil e de confecção cria diversos problemas ambientais. Ao longo da cadeia têxtil existem diversas operações que geram resíduos, desde o descaroçamento do algodão até restos de fio e tecidos nas confecções, variando estes rejeitos quantoa característica e quantidade (SINDITÊXTIL-SP, 2009). Segundo o SINDITÊXTIL-SP - Sindicato das Indústrias de Fiação e Tecelagem do Estado de São Paulo (2012), são produzidas, anualmente, 175 mil toneladas de aparas têxteis advindas somente dos descartes dasconfecções no Brasil (Figura 3).

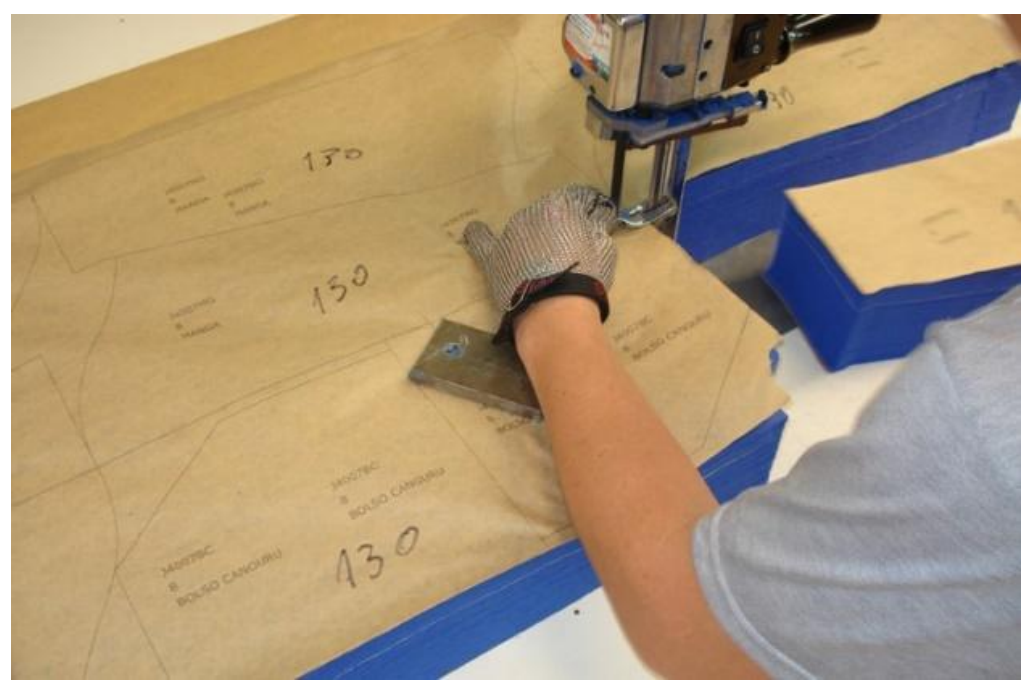

Figura 3: Operador de enfesto realizando o corte dos moldes com várias camadas de tecido sobrepostas. As sobras e rebarbas destes tecidos sobrepostos compõe o montante de 175 mil toneladas de resíduos anuais produzidos no país apenas pelas confecções

Fonte: (AUDACES, 2015)

Destas sobras, estima-se que mais de $80 \%$ tenham como destino os aterros sanitários ou o descarte ambientalmente incorreto (SEBRAE MERCADOS, 2015) e apenas o restante seja aproveitado pelas empresas têxteis recicladoras (SINDITÊXTIL-SP, 2012).

Em relação ao setor varejista, os desperdícios também são significativos. Segundo o "Projeto Contém", organização especializada em consumo sustentável, 9,8 bilhões de peças de confecção, oriundas de cerca de 30 mil empresas no Brasil, são produzidas por ano. Mais de 150 milhões não têm destinação definida e acabam estocadas ou destruídas. Em média, as coleções 
de moda têm vendas de $50 \%$ a $75 \%$ quando exposta no varejo e as sobras acabam em liquidações ou em bazares. O que não é vendido é doado, moído, depositado em aterros ou incinerado, podendo ser também exportado, em alguns casos (RADAR RIO+20, 2016).

À luz da Política Nacional de Resíduos Sólidos (PNRS) - Lei Federal 12.305 de 02 de Agosto de 2010 (BRASIL, 2010), a ABIT - Associação Brasileira da Indústria Têxtil e de Confecção (2015) publicou a "Agenda de Prioridades Têxtil e Confecção - 2015 a 2018", onde constam diversas ações relacionadas à sustentabilidade do setor têxtil-confeccionista. A principal delas diz respeito ao estímulo à utilização de matérias-primas de reuso ou recicladas através da desoneração de tributos, por exemplo.

\subsection{Atividades de reuso têxtil na região metropolitana do Rio de Janeiro: o exemplo do Projeto EcoModa}

Segundo Niinimäki (2011), o Estadopode contribuir para criação de valor da matéria-prima de reuso ou reciclada através de regulamentos, legislação e impostos. Além disso, as empresas que levarem em conta uma produção mais sustentável poderiam fazer avanços em sua rentabilidade e contribuir com a proteção do meio-ambiente (PAEHIKE, 2000). Munasinghe (2010) propõe que os produtores, através de procedimentos públicos de autoridade e legislação, devem estudar toda a cadeia de valor - desde as matérias-primas até os diversos estágios produtivos, além de focar também no gerenciamento da eliminação do produto, redefinindo seu valor de uma maneira completamente nova, em termos econômicos, sociais e ambientais.

No âmbito das Políticas Públicas do estado do Rio de Janeiro, existe o programa Niterói EcoCultural, que concentra cursos em três áreas distintas. Ele é realizado desde o final de 2015 por meio de uma parceria entre a Secretaria de Ambiente (Instituto Estadual do Ambiente - Inea) e a Prefeitura de Niterói (Fundação de Arte de Niterói - FAN). O referido programa é uma ação de conscientização sobre o descarte de resíduos sólidos, oferecendo atividades e 
formação aos moradores de 20 comunidades da cidade de Niterói, situada na região metropolitana do Rio de Janeiro (ECOCULTURALNITERÓI, 2016).

O EcoCultural tem o objetivo de alertar a população quanto ao descarte correto do lixo, cujo destino final, atualmente, são os rios e a Baía de Guanabara, além de garantir alternativas de renda para as famílias envolvidas por meio da reciclagem e do reuso de materiais. A meta, segundo o sítio eletrônico do projeto, é atingir aproximadamente 5 mil pessoas e contando com investimentos que somam R\$1,8 milhões (ECOCULTURALNITERÓI, 2016).

As oficinas de educação ambiental são realizadas pela Fundação de Arte de Niterói (FAN). A entidade também promove capacitação profissional de, aproximadamente, 400 indivíduos. Um dos cursos oferecidos é o de movelaria, por meio do projeto EcoDesign. Nele, os alunos aprendem sobre o reuso de materiais e trabalham no redesign das peças, ou seja, na projetação e produção de peças com valor agregado a partir das existentes(PREFEITURA DE NITERÓI, 2016).

O projeto EcoMúsica atua na construção de instrumentos musicais. Os alunos utilizam-se de latas, latões, tonéis, frigideiras, entre outros materiais, para produção de instrumentos de percussão, como, por exemplo, caixa, surdo, bumbo e chocalho. Juntamente com a construção desses instrumentos, os alunos também aprendem teoria musical e percussão (PREFEITURA DE NITERÓI, 2016).

Já o projeto EcoModa visa capacitar para o mercado formal da indústria do vestuário, também contribuindo para uma discussão sobre a redução do lixo urbano, posto que a moda tem sido uma ferramenta fundamental de diálogo entre o Estado e essas bases socioculturais. As matérias-primas, como aparas têxteis de diversas composições, artigos de vestuário e uniformes, são oriundas de diferentes doações, entre grandes e pequenos fornecedores (ECOCULTURALNITERÓI, 2016) (Figura 4). 


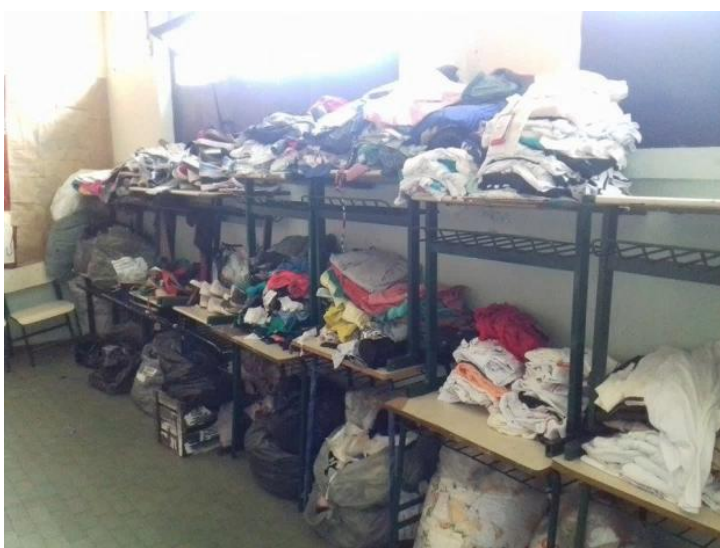

(a)

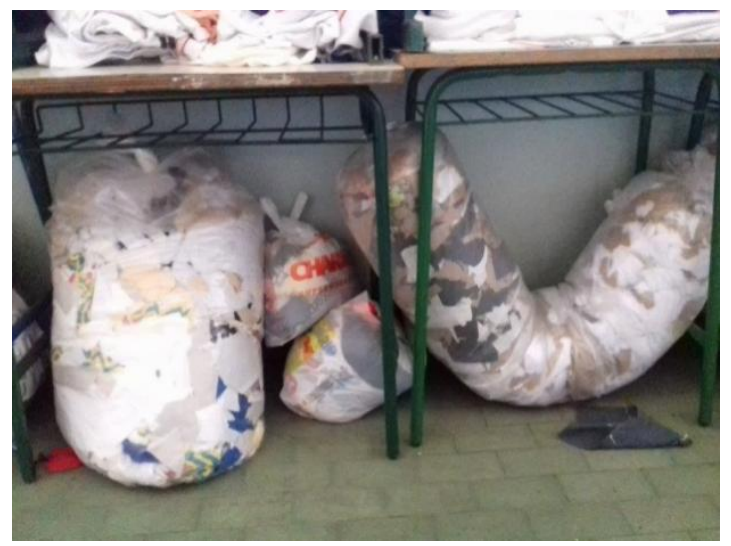

(b)

Figura 4: Doações recebidas pelo EcoModa: (a) roupas com defeitos e acessórios diversos; (b) aparas têxteis oriundas de confecções Fonte: (Fotos do autor, 2016)

Deste modo, o projeto serve como um laboratório para criações e experimentações na área do designde moda(ECOCULTURALNITERÓI, 2016).

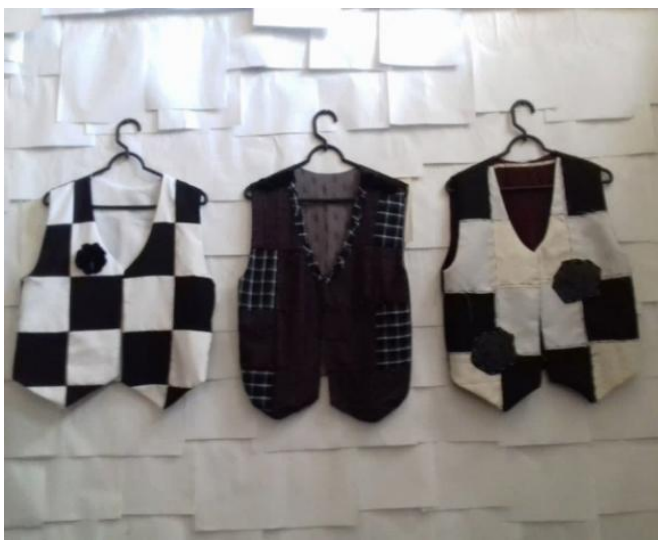

(a)

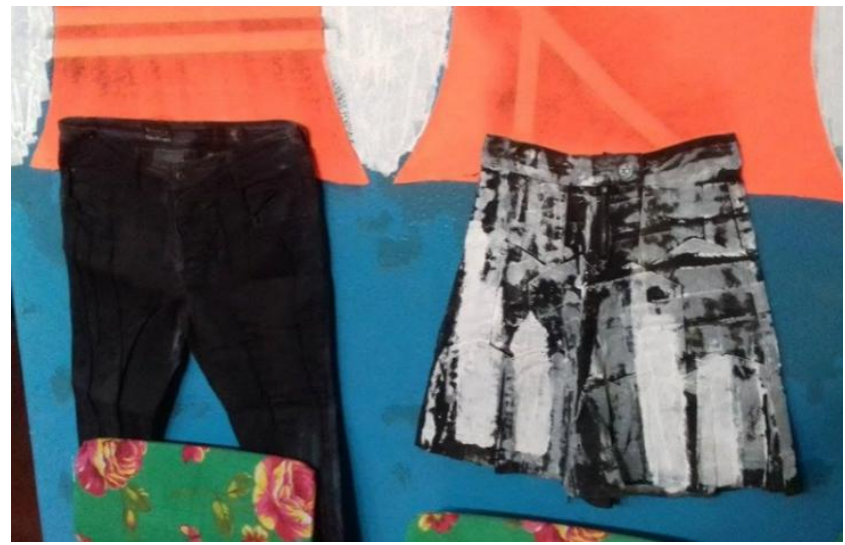

(b)

Figura 5: (a) coletes confeccionados pelos alunos com diferentes restos de tecidos; (b) peças de jeanswear customizadas pelos alunos do Projeto Fonte: (Fotos do autor, 2016)

\subsection{Atividades de reciclagem têxtil na região metropolitana do Rio de Janeiro}

Um dos principais problemas ambientais da cadeia têxtil é a geração de resíduos sólidos oriundos dos processos industriais, confeccionistas e também do pós-consumo. No caso das confecções, a geração de resíduos sólidos 
advém das sobras do processo de corte dos enfestos dos tecidos. O Brasil produz um volume significativo de retalhos oriundos de calças, camisas e meias, que poderiam ser reaproveitados por outras indústrias. No entanto, mais de $90 \%$ desses resíduos de tecido são descartados incorretamente (SINDITÊXTIL-SP, 2009).

Primeiramente, dentro da indústria têxtil e de confecção, atitudes devem ser tomadas para a não geração de resíduos. Os cuidados devem iniciar na escolha das matérias-primas até o descarte dos produtos pelo consumidor, com foco na minimização ou, se possível, na eliminação da geração de resíduos, que é a forma mais efetiva para combater a degradação do meio ambiente (LEITE, 2003). Assim, a orientação básica é a aplicaçãodos conceitos de Produção Mais Limpa $(P+L)$ denominados "3R's" de forma cíclica ou periódica, nesta ordem (SINDITÊXTIL-SP, 2009): i) Reduzir a geração de resíduos (nos processos produtivos e operações auxiliares); ii) Reusar os resíduos "inevitáveis" (aproveitá-los, sem quaisquer tratamentos); iii) Reciclar os resíduos "inevitáveis" (aproveitá-los após quaisquer tratamentos necessários dentro do processo ou mesmo fora do processo produtivo).

A atividade da reciclagem têxtil surgiu na cidade de Prato, na Itália, em meados do século XIX com a recuperação dos resíduos de lã (CAMARA DI COMMERCIO PRATO, 2016). Ela é caracterizada como a prática ou a técnica na qual os resíduos e sobras dos processos industriais, confeccionistas ou ainda oriundos do descarte de artigos confeccionados podem ser reprocessados, com a necessidade de tratamento para alterar as suas características físico-químicas ou não (SINDITÊXTIL-SP, 2009).

A reciclagem têxtil pode ser classificada dependendo das matériasprimas a serem reprocessadas, acarretando no uso de diferentes linhas de produção e processos específicos para obtenção dos produtos finais. Elas podem ser divididas em reciclagem mecânica, reciclagem química, mix de tecnologias e reciclagem térmica, conforme demonstrado na Figura 6 : 


\section{Resíduos têxteis}

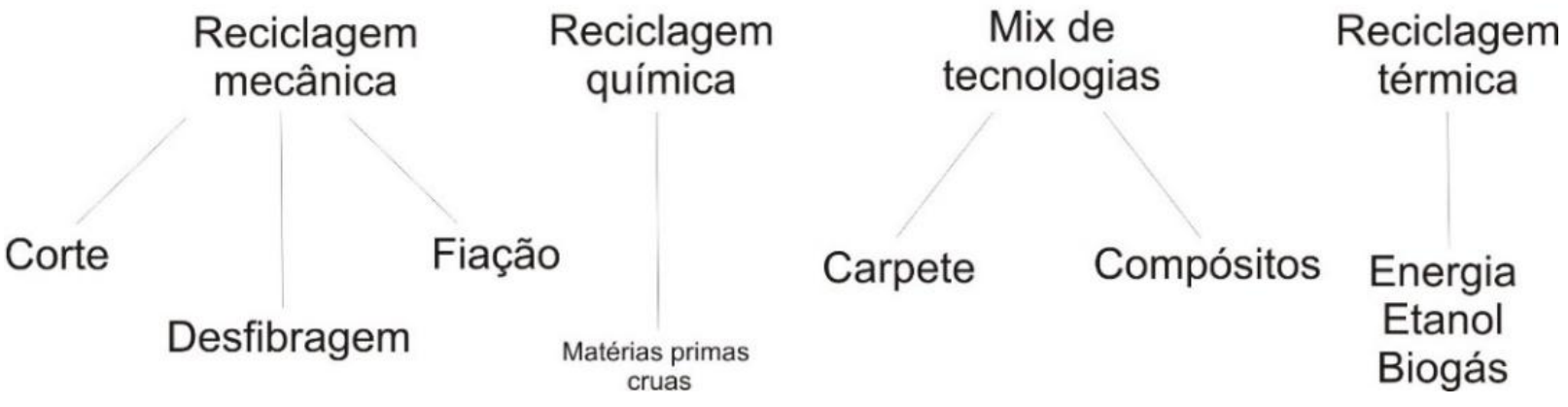

Figura 6: Tipos de reciclagem têxtil conforme o processo Fonte: (Adaptado de GROUPE CTT e ITS, 2016)

A reciclagem mecânica é a mais conhecida e difundida em nível industrial, podendo processar resíduos de diversas composições. Tanto as fibras virgens quanto as recicladas podem passar, posteriormente, pelos processos já conhecidos de fiação, diferenciando-se em um aspecto: os resíduos têxteis, podendo ser previamente separados por composição e cor (ou não, dependendo do produto final que se deseja obter), necessitam passar por um maquinário específico que os destrinche, uma vez que já estão consolidadas na forma de roupas, tecidos ou aparas (ZONATTI, 2013; ZONATTI, 2016).

Segundo Amaral (2016), que levantouem seu estudouma relação de indústrias nacionais de reciclagem têxtil, observa-se a inexistência deste tipo de atividade no Estado do Rio de Janeiro. Dentre as 21 empresas listadas, a maioria delas está situada no Estado de São Paulo, seguido pelo Estado de Santa Catarina.

\section{CONSIDERAÇÕES FINAIS}

No Estado do Rio de Janeiro não foram encontradas, até o presente momento, indústrias que reciclem os descartes têxteis. Em relação ao acesso às informações sobre reciclagem têxtil, observa-se que é bastante restrito, não sendo muito comum encontrá-las em artigos científicos, livros, apostilas, manuais ou sites da internet. Apenas a reciclagem têxtil mecânica é a mais 
divulgada e utilizada pelas indústrias do setor, posto que em sua linha de produção podem ser processados resíduos de diversas cores e composições. Contudo, no Brasil, tais indústrias concentram-se, principalmente, nos Estados de São Paulo e de Santa Catarina, podendo vir a ser um abundante campo de atuação o Estado do Rio de Janeiro, dado aos seus Arranjos Produtivos Locais.

Foram constatadas no Estado do Rio de Janeiroapenas atividades que reutilizam a referida matéria-prima, a exemplo do projeto social EcoModa na cidade deNiterói. Observa-se que o reuso dos resíduos têxteis por meio de ações de Políticas Públicas, ou seja, que visem a educação ambiental e a qualificação de mão-de-obra de comunidades relacionadas ao projeto, é campo fértil para experimentações criativas e produção de novas peças e acessórios de moda com apelo sustentável, além de contribuir com a preservação ao meio ambiente.

Deste modo, conclui-se que as atividades de reuso e de reciclagem têxtil é uma contribuição positiva para a destinação dos resíduos sólidos advindos das indústrias, confecções ou mesmo do descarte doméstico, dado ao volume significativo destese também dado ao seu destino incorreto, comumente dispostos em rios, baías e aterros sanitários. O reuso e a reciclagem têxtil também pode contribuir para a diminuição de problemas ambientais, além de constituir fonte de renda economicamente viável para todos envolvidos em sua cadeia.

\section{Agradecimentos}

Agradecemos ao Instituto Federal de Educação, Ciência e Tecnologia do Rio de Janeiro (IFRJ) pelo auxílio financeiro à presente pesquisa e pela Bolsa de Iniciação Científica institucional concedida. 


\section{REFERÊNCIAS}

ABIT - ASSOCIAÇÃO BRASILEIRA DA INDÚSTRIA TÊXTIL E DE CONFECÇÃO. Guia Têxtil 2011.Disponível em

$<$ http://www.guiatextil.com/site/noticias/industria/abit_esclarece_principais_duvi das_das_normas_de_vestibilidade>. Acesso em: 08 set. 2016.

ABIT - ASSOCIAÇÃO BRASILEIRA DA INDÚSTRIA TÊXTIL E DE CONFECÇÃO. Agenda de Prioridades Têxtil e Confecção - 2015/2018. São Paulo: ABIT, 2015. 35 p.

AUDACES - A TECNOLOGIA DA MODA. Garanta mais simplicidade na resolução das ordens de corte com Neoplan. Disponível em $<$ https://robmaqmoda.wordpress.com/category/uncategorized/page/6/>. Acesso em: 26 jan. 2015.

AMARAL, M.C. do.Reaproveitamento e reciclagem têxtil no Brasil: ações e prospecto de triagem de resíduos para pequenos geradores. 2016. $119 \mathrm{p}$. Dissertação (Mestrado em Têxtil e Moda). Escola de Artes, Ciências e Humanidades da Universidade de São Paulo. São Paulo/SP, 2016.

BASRA, A. S.; MALIK, C. P.Development of the Cotton Fiber. Intern.Rev. of Cyt., v. 89, p. 65-113, 1984.

BRASIL. Política Nacional de Resíduos Sólidos - Lei no 12.305, de 2 de agosto de 2010. Institui a Política Nacional de Resíduos Sólidos; altera a Lei no 9.605, de 12 de fevereiro de 1998; e dá outras providências, 2010.

CAMARA DI COMMERCIO PRATO.Cardato Regenerated $\mathrm{CO}_{2}$ Neutral. Disponível em $<$ file://C:/Users/W/Downloads/Prato_Chamber_of_Commerce_project_descripti on.pdf>. Acesso em: 23 out. 2016.

ECOCULTURAL NITERÓI. Oficinas de Moda Chegam a Comunidades de Niterói. Disponível em $<$ http://ecoculturalniteroi.com.br/blog/?id=1748\&equ=ecocultural $>$ Acesso: em 10 jun. 2016. 
FINKLER, M. et al. Compósitos de HDPE com Resíduos de Fibras Têxteis. Parte I: Caracterização Mecânica. Pol: Ciên. e Tecn., vol. 15, n. 3, p. 171-175, 2005.

GEISON, G. L. The private science of Louis Pasteur. New Jersey: Princeton University Press, 1995.

GIL, A. C. Métodos e Técnicas de Pesquisa Social. 6 ed. São Paulo: Atlas, 2008.

GROUPE CTT - CENTRE MULTISERVICES POUR L'INDUSTRIE TEXTILE e ITS - INSTITUTE OF TEXTILE SCIENCE. Textile recycling: an overview on technologies and tendencies applications. Disponível em <http://www.textilescience.ca/downloads/april12_2013/Recycling_Claire_Guigni er_apr12_2013.pdf>. Acesso em: 10 nov. 2016.

IEMI - INSTITUTO DE ESTUDOS E MARKETING INDUSTRIAL. Relatório Setorial da Indústria Têxtil Brasileira - Brasil Têxtil 2014. 14를 edição. São Paulo, 2014.

IEMI - INSTITUTO DE ESTUDOS E MARKETING INDUSTRIAL. Relatório Setorial da Indústria Têxtil Brasileira - Brasil Têxtil 2015. 15ª edição. São Paulo, 2015.

IPT - INSTITUTOS DE PESQUISAS TECNOLÓGICAS. As faces da Ciências. Disponível em <http://www.ipt.br/noticias_interna.php?id_noticia=609> Acesso em: 29 de Ago. de 2016.

KATES, R. W. et al.Sustainability Science. Sci. Mag., v. 292, n. 5517, p. 641642, 2001.

LAGO, A. A. C. Estocolmo, Rio, Joanesburgo: o Brasil e a três conferências ambientais das Nações Unidas. Brasília:FUNAG/IRBr, 2006. $274 p$.

LEITE, P. R.Logística reversa: meio ambiente e competitividade. São Paulo: Ed. Prentice-Hall, 2003.

MARCONI, M. A.; LAKATOS, E. M. Técnicas de pesquisa: planejamento e execução de pesquisas, amostragens e técnicas de pesquisas, elaboração, análise e interpretação de dados, 5 ed. São Paulo: Atlas, 2002. 
MARTINS, G. A. Metodologias Convencionais e Não convencionais e a pesquisa em Administração. Caderno de Pesquisas em Administração. São Paulo, 1994.

MATTOS, P. T. L.O Novo Estado Regulador no Brasil: Eficiência e Legitimidade. São Paulo: Ed. Singular,2006. 331 p.

MELLO, M. B. C. et al. Inovações Tecnológicas na Cadeia produtiva Têxtil: Análise e estudo de caso em Indústria do nordeste do Brasil. Rev. Prod. On Line, v. 7, n. 2, p. 99-117, 2007.

MELO NETO, G.; STACCIARINI, J. H. R.Educação Ambiental: da disciplinaridade à transdisciplinaridade ao pensamento complexo. In: Anais do II SEAT - Simpósio de Educação Ambiental e Transdisciplinaridade, UFG/IESA/NUPEAT, Goiânia, Maio de 2011.

MUNASINGHE, M.Can Sustainable Consumers and Producers Save the Planet?. Jour. of Ind. Ecol., v. 14, n. 1, p. 4-6, 2010.

NAS - NATIONAL ACADEMY OF SCIENCES. Sustainability Science: a room of its own. Proceedings of the National Academy of Sciences (PNAS), v. 104, n. 06, p. 1737-1738, 2007.

NEULS, G. Economia movida a $\mathbf{C O}_{2}$. Página 22 (Escola de Administração de Empresas de São Paulo da Fundação Getúlio Vargas), n. 68. São Paulo: Ed. Vox.

NIINIMÄKI, K.From Disposable to Sustainable - The Complex Interplay between Design and Consumption of Textiles and Clothing. 2011. 293 p. Thesis (PhD in Design). School of Art and Design of Aalto University. Helsinki, 2011.

PAEHIKE, R. C. Environmental values and publicpolicy. In: N. J. Vig; M. E. Kraft (Eds.), Environmental Policy. 4th edition. Washington: CQ Press, p. 77-97, 2000.

PEREIRA, U. C.Sustentabilidade: da teoria à prática - por uma educação ambiental transformadora. In: Anais do II SEAT - Simpósio de Educação Ambiental e Transdisciplinaridade, UFG/IESA/NUPEAT, Goiânia, Maio de 2011.

PREFEITURA DE NITERÓI.Programa Recicla Niterói vai inaugurar Centro de Ofícios da Reciclagem no Barreto. Disponível em 
<http://www.niteroi.rj.gov.br/index.php?option=com_content\&view=article\&id=39 76:2016-04-19-13-11-34> Acesso em: 10 jun. 2016.

RADAR RIO+20.Reciclagem avança como destino de roupa encalhada. Disponível em <http://www.radarrio20.org.br/index.php?r=noticias/view\&id=238951 >. Acesso em: 26 out. 2016.

SEBRAE MERCADOS. Retalhos de tecidos: no lugar do desperdício, negócios sustentáveis. Disponível em

$<$ http://www.sebraemercados.com.br/retalhos-de-tecidos-nolugar-dodesperdicio-negocios-sustentaveis/>. Acesso em: 25 ou. 2015.

SEDEIS - SECRETARIA DE DESENVOLVIMENTO ECONÔMICO, ENERGIA, INDÚSTRIA E SERVIÇOS DO ESTADO DO RIO DE JANEIRO. Arranjos Produtivos Locais. Disponível em <www.desenvolvimento.gov.br/arquivos/dwnl_1310055560.pdf> Acesso em: 29 de Ago. de 2016.

SILVA, D. O Paradigma transdisciplinar: uma perspectiva metodológica para a pesquisa ambiental. In: Philippi Jr., Arlindo (Org.). Interdisciplinaridade em Ciências Ambientais. São Paulo: Signus, 2000.

SINDFIATEC - SINDICATO DE FIAÇÃO E TECELAGEM EM GERAL CAMPINAS E REGIÃO. Apresentado mapeamento inédito do setor têxtil em São Paulo. Disponível em

<http://www.sindfiatec.com.br/home/index.php?option=com_content\&view=artic le\&id=111: apresentado-mapeamento-inedito-do-setor-textil-emsaopaulo\&catid=21:noticias\&ltemid=165>. Acesso em: 25 mar. 2013.

SINDITÊXTIL-SP - SINDICATO DAS INDÚSTRIAS DE FIAÇÃO E TECELAGEM DO ESTADO DE SÃO PAULO. Guia técnico ambiental da indústria têxtil - Série P+L. São Paulo: CETESB: SINDITÊXTIL-SP, 2009.

SINDITÊXTIL-SP - SINDICATO DAS INDÚSTRIAS DE FIAÇÃO E TECELAGEM DO ESTADO DE SÃO PAULO. Retalho Fashion - Projeto de reciclagem une meio ambiente e inclusão social. Ano VII, n. 25, Julho de 2012.

STOKES, D. E. O Quadrante de Pasteur: a ciência básica e a inovação tecnológica. Campinas: Ed. da Unicamp, 2008. 
TOZONI-REIS, M. F. C.Formação dos educadores ambientais e paradigmas em transição. Ciên. \& Ed., v.8, n. 1, p.83 - 96, 2002.

UNITED NATIONS. Sustenaible development knowledge plataform.

Disponível em <http://sustainabledevelopment.un.org/> Acesso em: 25 out. 2016.

VERGARA, S. C. Métodos de Pesquisa em Administração. São Paulo: Atlas, 2000.

YOUNG, L.; HAMSHIRE, J. Promoting practical sustainability. Canberra (Australia): Australian Agency for International Development (AUSAID), 2000.

ZONATTI, W. F. Estudo interdisciplinar entre reciclagem têxtil e o design: avaliação de compósitos produzidos com fibras de algodão. 2013. 177 p. Dissertação (Mestrado em Têxtil e Moda). Escola de Artes, Ciências e Humanidades da Universidade de São Paulo. São Paulo/SP, 2013.

ZONATTI, W. F. Geração de Resíduos Sólidos da Indústria Brasileira Têxtil e de Confecção: materiais e processos para reuso e reciclagem. 2016. 250 p. Tese (Doutorado em Sustentabilidade). Escola de Artes, Ciências e Humanidades da Universidade de São Paulo. São Paulo/SP, 2016. 